\title{
GENETIC POLYMORPHISM OF THE B SUBUNIT OF HUMAN COAGULATION FACTOR XIII IN JAPANESE
}

\author{
Toshinori Nishigaki and Keiichi Oмото \\ Department of Anthropology, Faculty of Science, \\ The University of Tokyo, Tokyo 113, Japan
}

\begin{abstract}
Summary Polymorphism of the B subunit of human coagulation factor XIII was investigated in a total of 119 plasma samples from unrelated adult Japanese using agarose gel electrophoresis followed by immunofixation. Three common phenotypes were observed, which corresponded to the types 1, 1-3 and 3 reported by Board (1980) in Australians. The estimated allele frequencies of $F 13 B^{*} 1$ and $F 13 B^{*} 3$ were 0.303 and 0.697 , respectively. The observed numbers of the phenotypes were in good agreement with those expected on the basis of Hardy-Weinberg's law. These results are not inconsistent with the hypothesis that these phenotypes are controlled by a pair of autosomal, codominant alleles.
\end{abstract}

\section{INTRODUCTION}

Factor XIII (fibrin stabilizing factor) is the precursor of the transamidating enzyme which acts in the final step of the blood coagulation process. After activation by thrombin, in the presence of $\mathrm{Ca}^{2+}$, activated factor XIII catalyzes the formation of $\gamma$-glutamyl- $\varepsilon$-lysine crosslinks between fibrin monomers to produce insoluble fibrin (for review see Folk and Finlayson, 1977). It is generally considered that factor XIII from plasma is a tetramer composed of two A subunits and two $B$ subunits $\left(A_{2} B_{2}\right)$ (Schwartz et al., 1973). The B subunits have no enzymatic activity. There have been a few suggestions concerning the function of the B subunit for which experimental support was presented, namely, control of the rate of activation by thrombin (Chung et al., 1974), regulation of calcium-dependent activation (Lorand et al., 1974) and preventing rapid catabolism of plasma factor XIII (Lee and Chung, 1976).

Genetic polymorphism of the A subunit was recently described in Australian (Board, 1979), Japanese (Nishigaki et al., 1981; Kera and Nishimukai, 1982) and a few populations from the Pacific region (Board and Coggan, 1981). Also, polymorphism of the B subunit was first described by Board (1980) in Australian Caucasians by agarose gel electrophoresis followed by immunofixation. The pheno-

Received March 29, 1982 
types were shown to be controlled by three codominant alleles on an autosomal locus (Board, 1980).

Recently, Kera et al. (1981) investigated a sample of Japanese using isoelectric focusing followed by immunofixation. They reported three phenotypes which they referred to as type F, FS and S on the basis of the nomenclature which differs from that of Board (1980). In this paper, we report the results of our investigation in which the method for typing and the nomenclature were the same as in Board (1980).

\section{MATERIALS AND METHODS}

A total of 119 ACD plasma samples from unrelated blood donors living in Tokyo were used for population study. Samples were stored in liquid nitrogen until use.

Agarose gel electrophoresis was carried out using the method of Board (1979) with slight modifications as previously described (Nishigaki et al., 1981). Electrophoresis was carried out until a hemoglobin marker migrated about $8 \mathrm{~cm}$ from the origin.

After electrophoresis, the B subunits were localized on the gel by immunofixation with a $30 \%(\mathrm{v} / \mathrm{v})$ solution of rabbit anti-human factor XIII subunit $\mathrm{S}$ antiserum (Behringwerke AG, Marburg, West Germany), essentially following the method described by Board (1979). " $\mathrm{S}$ " and " $B$ " refer to the same subunit.

\section{RESULTS}

Three different patterns were observed by the present electrophoretic survey of plasma samples from blood donors living in Tokyo (Fig. 1). These patterns may be readily explained by the presence of polymorphism based on a pair of alleles, one determining a fast and the other a slow migrating double-banded component. Two bands of each pair were spaced at intervals of $0.6 \mathrm{~cm}$. When a hemoglobin marker migrated at $8 \mathrm{~cm}$, the fast pair was located at $2 \mathrm{~cm}$ and the slow pair was located at $3.5 \mathrm{~cm}$ behind the marker. One or more minor bands which migrated on the anodal side of each major component were occasionally observed. Judging from relative position of each component, the three phenotypes observed in the present study were considered to be identical with $1,1-3$ and 3 reported by Board (1980) in Australian Caucasians.

The distribution of phenotypes in 119 unrelated samples are presented in Table 1. The allele frequencies of $F 13 B^{*} l$ and $F 13 B^{*} 3$ were estimated at 0.303 and 0.697 , respectively.

\section{DISCUSSION}

In Australian population, besides $F 13 B^{*} 1$ and $F 13 B^{*} 3$, another allele $F 13 B^{* 2}$ which controls the intermediate component between two components controlled 


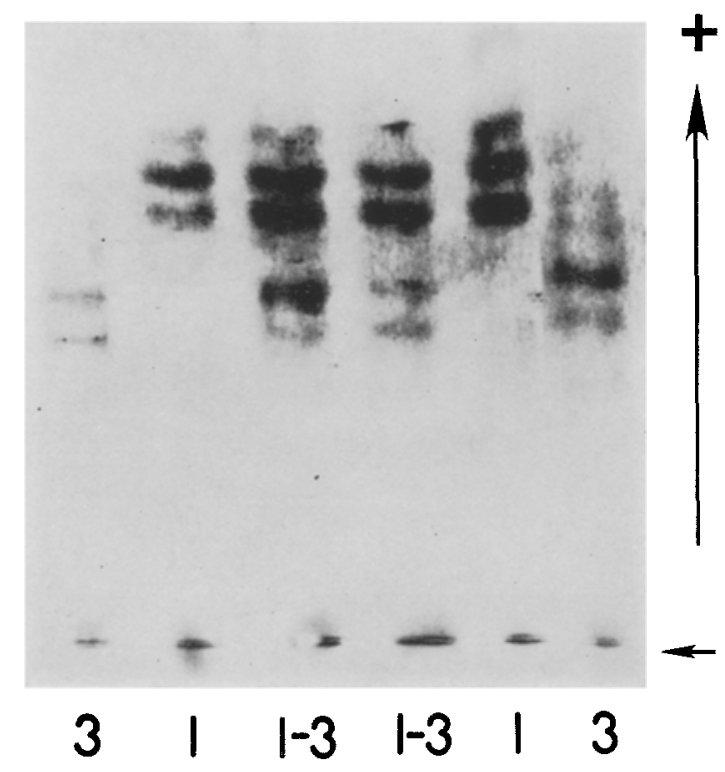

Fig. 1. Immunofixation patterns of factor XIII-B following agarose gel electrophoresis.

Table 1. Distribution of factor XIII-B phenotypes and allele frequencies in a Japanese population.

\begin{tabular}{ccccl} 
& \multicolumn{3}{c}{ Phenotypes } & Total \\
\cline { 2 - 4 } & 1 & $1-3$ & 3 & \\
\hline Obs. No. & 11 & 50 & 58 & 119 \\
$\%$ & 9.2 & 42.0 & 48.8 & 100.0 \\
Exp. No. & 10.9 & 50.3 & 57.8 & 119.0 \\
\hline
\end{tabular}

$\chi^{2}=0.003$. d.f. $=1 . \quad 0.9<$ p.

allele frequencies: $F 13 B^{*} 1=0.303, F 13 B^{*} 3=0.697$.

by $F 13 B^{*} 1$ and $F 13 B^{*} 3$ was reported by Board (1980), and the phenotype 1-2 and 2-3 were observed (Board, 1980). In the present study, however, phenotype 1-2, 2 and 2-3 were not observed. In Japanese, it appears that the allele $F 13 B^{* 2} 2$ is absent or that the frequency of $F 13 B^{*} 2$ is very low.

In comparison with Australian population, the allele frequency of $F 13 B^{*} 3$ is much higher and that of $F 13 B^{*} l$ is much lower in Japanese population (Table 2). On the other hand, only a small differences in the allele frequency of the A subunit among various populations is observed (Table 3 ). It poses an interesting problem as to whether the allele frequencies of the B subunit which has no enzymatic activity are much more variable among different populations than those of the A subunit which has enzymatic activity, although sample number thus far reported is still very small. 
Table 2. Comparison of allele frequencies of factor XIII-B between two populations.

\begin{tabular}{lccccc} 
& $\mathrm{N}$ & $F 13 B^{* 1}$ & $F 13 B^{* 2}$ & $F 13 B^{* 3}$ & \\
\cline { 1 - 5 } $\begin{array}{l}\text { Australian } \\
\text { Japanese }\end{array}$ & 245 & 0.747 & 0.084 & 0.169 & Board (1980) \\
\hline
\end{tabular}

Tabie 3. Allele frequencies of factor XIII-A in various populations.

\begin{tabular}{|c|c|c|c|c|c|}
\hline Population & $\mathrm{N}$ & $F 13 A^{*} l$ & $F 13 A^{*} 2$ & $F 13 A^{*} 4$ & Authors \\
\hline Australian & 179 & 0.79 & 0.21 & - & Board (1979) \\
\hline \multicolumn{6}{|l|}{ Fiji } \\
\hline Melanesian & 127 & 0.783 & 0.209 & 0.008 & Board and Coggan (1981) \\
\hline Indian & 127 & 0.768 & 0.232 & - & \\
\hline \multicolumn{6}{|l|}{ Loyalty Is. } \\
\hline Melanesian & 133 & 0.925 & 0.075 & - & \\
\hline \multicolumn{6}{|l|}{ Cook Is. } \\
\hline Polynesian & 100 & 0.980 & 0.020 & - & \\
\hline Japanese & 561 & 0.887 & 0.113 & - & Nishigaki et al. (1981) \\
\hline
\end{tabular}

As to the mode of inheritance of a congenital factor XIII deficiency, possibility of a sex-linkage was suggested (Hampton et al., 1966; Ratnoff and Steinberg, 1968, 1972; Steinberg and Ratnoff, 1970), while recent reports indicated an autosomal recessive inheritance (McDonagh et al., 1971, 1974; Barbui et al., 1978). Each structural locus of the A and B subunits of the factor XIII was recently shown to be on an autosomal chromosome by the investigation of their genetically controlled electrophoretic variation (Board, 1979, 1980; Nishigaki et al., 1981; Kera et al., 1981; Kera and Nishimukai, 1982). The observed numbers of phenotypes in the present study were in good agreement with those expected under Hardy-Weinberg equilibrium (Table 1). This result is also consistent with the hypothesis that the polymorphism of the B subunit is controlled by a pair of codominant alleles at an autosomal locus.

It has been described that in the case of deficiency of the A subunit, the B subunit is also decreased or absent (Barbui et al., 1978; Girolami et al., 1978; Board et al., 1980). In the present study, no significant difference of staining intensity was observed among the different combination of phenotypes of two subunits. The staining intensity of the $F 13 B^{*} 3$ products, however, tended to be lower than that of the $F 13 B^{*} 1$ products as described by Board (1980) (Fig. 1).

Recently, Kera et al. (1981) reported genetic polymorphism of the B subunit in Japanese using isoelectric focusing followed by immunofixation. They observed three phenotypes in Japanese population which they called F, FS and S. They described that each phenotype contains three types which differ in the intensity of 
bands due to the contents of sialic acid (e.g. F : $\mathrm{F}_{1}, \mathrm{~F}_{2}, \mathrm{~F}_{3}$ ) and that the patterns of $F_{1}$ (or $F_{2}$ ) and $S_{2}$ are similar to those of 1-2 and 2-3 reported by Board (1980), respectively. However, it is not known whether the phenotypes typed by two different methods are identical, because no photograph of agarose gel electrophoretic patterns of $F_{1}, F_{2}$ and $S_{2}$ was presented by Kera et al. (1981). In the present survey by agarose gel electrophoresis, phenotypes 1-2, 2 and 2-3 were not observed. Further studies seem to be necessary to confirm whether phenotype 1-2 and 2-3 reported by Board (1980) are attributable to postsynthetic sialidation. The allele frequencies reported by Kera et al. (1981), $F-X I I I B^{\mathrm{F}}=0.336$ and $F-X I I I B^{\mathrm{S}}=0.664$, are not statistically different from those of the present study, namely, $F 13 B^{*} 1=$ 0.303 and $F 13 B^{*} 3=0.697\left(\chi^{2}=0.837\right.$, d.f. $\left.=1,0.3<\mathrm{p}<0.4\right)$. Therefore, type $F$, FS and $S$ reported by Kera et al. (1981) seem to correspond to type 1, 1-3 and 3 in the present study, respectively.

Genetic polymorphism of the B subunit as well as the A subunit of factor XIII is a useful marker in human genetics for population studies. The heterogeneity of factor XIII deficiency was previously suggested (Ukita et al., 1976; Forman et al., 1977). The electrophoretic examination provides with a useful technique for its analysis (Stenberg and Stenflo, 1979; Board et al., 1980; Castle et al., 1981). Using two-dimensional immunoelectrophoresis, Barbui et al. (1974) reported a case of factor XIII deficiency with the B subunit differing from that of normal control. In such investigations, it seems to be necessary that genetic polymorphisms of these subunits are taken into consideration.

Acknowledgment We wish to express our gratitudes to Mr Uchikawa, Blood Transfusion Service, Tokyo University Hospital for providing us with blood samples. Thanks are also due to Dr. P.G. Board, Department of Human Biology, John Curtin School of Medical Research, Australian National University for valuable advice in the initial stage of this study.

\section{REFERENCES}

Baubui, T., Cartei, G., Chisesi, T., and Dini, E. 1974. Electroimmunoassay of plasma subunits -A and $-\mathrm{S}$ in a case of congenital fibrin stabilizing factor deficiency. Thromb. Diath. Haemorrh. (Stuttg.) 32: 124-131.

Barbui, T., Rodeghiero, F., Dini, E., Mariani, G., Papa, M.L., DeBiasi, R., Cordero-Murillo, R., and Montero-Umana, C. 1978. Subunits A and S inheritance in four families with congenital factor XIII deficiency. Br. J. Haematol. 38: 267-271.

Board, P.G. 1979. Genetic polymorphism of the A subunit of human coagulation factor XIII. Am. J. Hum. Genet. 31: 116-124.

Board, P.G. 1980. Genetic polymorphism of the B subunit of human coagulation factor XIII. Am. J. Hum. Genet. 32: 348-353.

Board, P.G., Coggan, M., and Hamer, J.W. 1980. An electrophoretic and quantitative analysis of coagulation factor XIII in normal and deficient subjects. Br. J. Haematol. 45: 633-640.

Board, P.G., and Coggan, M. 1981. Polymorphism of the A subunit of coagulation factor XIII in the Pacific region: Description of new phenotypes. Hum. Genet. 59: 135-136.

Castle, S., Board, P.G., and Anderson, R.A.M. 1981. Genetic heterogeneity of factor XIII deficiency: First description of unstable A subunits. Br. J. Haematol. 48: 337-342. 
Chung, S.I., Marc, S.L., and Folk, J.E. 1974. Relationship of the catalytic properties of human plasma and platelets transglutaminases (activated blood coagulation factor XIII) to their subunit structures. J. Biol. Chem. 249: 94-950

Folk, J.E., and Finlayson, J.S. 1977. The $\varepsilon$ - $(\gamma$-glutamyl)lysin crosslink and the catalytic role of transglutaminases. Adv. Protein Chem. 31: 2-133.

Forman, W.B., Byer, R., Hadady, M., Krill, C., and Lubin, A. 1977. Congenital fibrin stabilizing factor deficiency: evidence for Dys-FSF. Blood $\mathbf{5 0}$ (Suppl. 1): 266.

Girolami, A., Burul, A., Fabris, F., Cappellato, G., and Betterle, C. 1978. Studies on factor XIII antigen in congenital factor XIII deficiency. A tentative classification of the disease in two groups. Folia. Haematol. Leipzig 105: 131-141.

Hampton, J.W., Cunningham, G.R., and Bird, R.M. 1966. The pattern of inheritance of defective fibrinase (factor XIII). J. Lab. Clin. Med. 67: 914-921.

Kera, Y., Nishimukai, H., and Yamasawa, K. 1981. Genetic polymorphism of the B subunit of human coagulation factor XIII: Another classification. Hum. Genet. 59: 360-364.

Kera, Y., and Nishimukai, H. 1982. Genetic polymorphism of the A subunit of human coagulation factor XIII in Japanese. Hum. Hered. 32: 216-218.

Lee, S.Y., and Chung, S.I. 1975. Biosynthesis and degradation of plasma protransglutaminase (factor XIII). Fed. Proc., Fed. Am. Soc. Exp. Biol. 35: 1486.

Lorand, L., Gray, A.J., Brown, K., Credo, R.B., and Curtis, C.G. 1974. Dissociation of the subunit structure of fibrin stabilizing factor during activation of zymogen. Biochem. Biophys. Res. Commun. 56: 914-922.

McDonagh, J., McDonagh, R.P., Jr., and Duckert, F. 1971. Genetic aspects of factor XIII deficiency, Ann. Hum. Genet. (Lond.) 35: 197-206.

McDonagh, J., McDonagh, R.P., Myllyä, G., and Ikkala, E. 1974. Factor XIII deficiency: a genetic study of two affected kindreds in Finland. Blood 43: 327-332.

Nishigaki, T., Omoto, K., and Juji, T. 1981. Genetic polymorphism of the A subunit of human coagulation factor XIII in Japanese. Jpn. J. Human Genet. 26, 237-241.

Ratnoff, O.D., and Steinberg, A.G. 1968. Inheritance of fibrin stabilizing factor deficiency. Lancet 1: $25-26$.

Ratnoff, O.D., and Steinberg, A.G. 1972. Fibrin crosslinking and heredity. Ann. N.Y. Acad. Sci. 202: 186-189.

Schwartz, M.L., Pizzo, S.V., Hill, R.L., and MuKee, P.A. 1973, Human factor XIII from plasma and platelets; Molecular weights, subunit structure, proteolytic activation and cross-linking of fibrinogen and fibrin. J. Biol. Chem. 248: 1395-1407.

Steinberg, A.G., and Ratnoff, O.D. 1970. Inheritance of factor XIII. Am. J. Hum. Genet. 22: 597-598.

Steinberg, P., and Stenflo, J. 1979. A rapid and specific fluorescent activity staining procedure for transamidating enzymes. Anal. Biochem. 93: 445-452.

Ukita, M., Mikami, T., Mikami, K., Kitahara, T., Kato, M., and Kani, T. 1976. Studies on abnormal protein in seven patients with congenital factor XIII deficiency. (in Japanese) Jpn. J. Clin. Path. 34: 281-285. 